\title{
LA INTERACCIÓN ENTRE EGIPCIOS Y NUBIOS A FINALES DEL REINO MEDIO: DEL TOPOS A LA VIDA COTIDIANA
}

\author{
The Interactions Between Egyptians and Nubians in the Late Middle Kingdom: from \\ Topos to Daily Life
}

\author{
Javier GonZÁLEZ-TABLAS NieTO ${ }^{1}$ \\ Dpto. Prehistioria, $\mathrm{H}^{\mathrm{a}}$ Antigua y Arqueología \\ Facultad de Geografía e Historia \\ Universidad de Salamanca \\ E-mail: jgtablas@usal.es
}

Fecha de recepción: 6-III-2011

Fecha de aceptación: 30-III-2011

Resumen: Una de las constantes en la iconografía egipcia de todos los periodos es la visión que los egipcios tenían del mundo que les rodeaba, y, sobre todo, de las gentes que lo habitaban. Dentro de esta visión, hay dos versiones radicalmente distintas. Por un lado, están los textos e imágenes oficiales, cargados de agresividad, y que niegan a los pueblos extranjeros su propia soberanía, ya que sus tierras pertenecían legítimamente al faraón. Pero, por otra parte, gracias a los hallazgos de algunos textos cotidianos y a los datos aportados por la arqueología, se puede vislumbrar lo que en realidad sucedía en las zonas de interacción pese a esta visión oficial. Un buen ejemplo de esta contradicción es el que se analizará en este artículo, la Baja Nubia, donde coincidieron en el espacio y el tiempo tres culturas: egipcios, el denominado como Grupo C y los medyain. A esto se le añade la frontera con Kerma, en la Alta Nubia, cultura en ascenso que en el II Periodo Intermedio llegó a dominar el sur de Egipto.

Palabras clave: Egipto faraónico, Nubia, fortalezas, interacción, relaciones diplomáticas

AвSTRACT: One of the constants in Egyptian iconography from almost all of the periods is the view that the Egyptians had of the world that surrounded them, and of

1 Este artículo se ha redactado en el marco de una ayuda para la Formación del Personal Investigador de la Universidad de Salamanca, financiada por el Banco Santander. 
course, of the people that inhabited it. In this view, there are two different versions. On one side, the official and ideological texts and images, full of agressiveness, denying foreign people their own sovereignty, since their lands belonged to the Pharaoh. On the other hand, thanks to the discovery of some daily texts and to archaeological data, the real interactions in these regions can be seen, despite the official views. A good example of this will be analyzed in this paper: Lower Nubia, where three cultures coexisted in the same space and time: the Egyptians, Group C and Medjay, plus the frontier region with Kerma, an ascending culture which would dominate the southern part of Egypt in the II Intermediate Period.

Keywords: Pharaonic Egypt, Nubia, fortresses, interaction, diplomatic relationships.

\section{Nubia y los Nubios}

Se utiliza el término Nubia para denominar la región situada al sur de Egipto, cuyo territorio coincide aproximadamente con el moderno Sudán. Esta región vio florecer a orillas del Nilo a una de las primeras civilizaciones del mundo antiguo, pese a que no se haya comenzado a conocer hasta hace relativamente poco tiempo. Dos son las razones principales que explican el relativo desconocimiento de la cultura nubia: en primer lugar, la ausencia de fuentes escritas de los propios nubios hasta la época meroítica y el hecho de que las pocas que se conservan sean en lengua egipcia, ha hecho que el conocimiento textual sea muy dependiente de las fuentes egipcias. En segundo lugar, y muy relacionado con esto, la visión egiptocéntrica de las investigaciones, que trataba a los nubios como un pueblo disperso, incivilizado y a la sombra de una gran cultura, Egipto. Como se verá en las próximas páginas, estos argumentos no son ya sostenibles, especialmente a partir de las grandes campañas de excavación arqueológica de los años 60 con motivo de la construcción de la gran presa de Asuán.

Así pues, hoy se sabe que del mismo modo que sucede con Egipto, Nubia se articulaba en torno al Nilo, fuente de toda su riqueza, y también igual que Egipto, se dividía en la Alta y la Baja Nubia. La Alta Nubia, desde la Sexta Catarata al sur hasta la Segunda Catarata al norte, se corresponde en el Reino Medio egipcio con la cultura Kerma —el kろš egipcio-. La Baja Nubia - w 3 w 3 - era el territorio comprendido entre Elefantina y la región de Buhen, en la Segunda Catarata.

Nubia estaba poblada por tres culturas principalmente: el Grupo C en la Baja Nubia, la cultura Kerma en la Alta Nubia y los medyaiu en el Desierto Oriental. Se denomina Grupo C a la cultura nativa de la Baja Nubia, que se desarrolló entre el 2400 y el 1550 a. C. aproximadamente (O'ConNOR, 1993: 7). Originariamente nómadas, experimentaron un proceso de sedentarización que culminó en el momento equivalente al Segundo Periodo Intermedio egipcio. Fueron probablemente el grupo que más contacto tuvo con Egipto, y, aunque sus relaciones fueron eminentemente pacíficas, ambas culturas mostraron una fuerte resistencia cultural y económica (SMTH, 1995: 49). La principal ocupación fue 
la ganadería, doméstica y salvaje, ya que las condiciones que la crecida del Nilo creaba para el pastoreo eran idóneas. Asociadas a esta actividad estarían la explotación de carne y leche como principales modos de subsistencia (Smith, 1995: 33-35; Trigger, 1965:15).

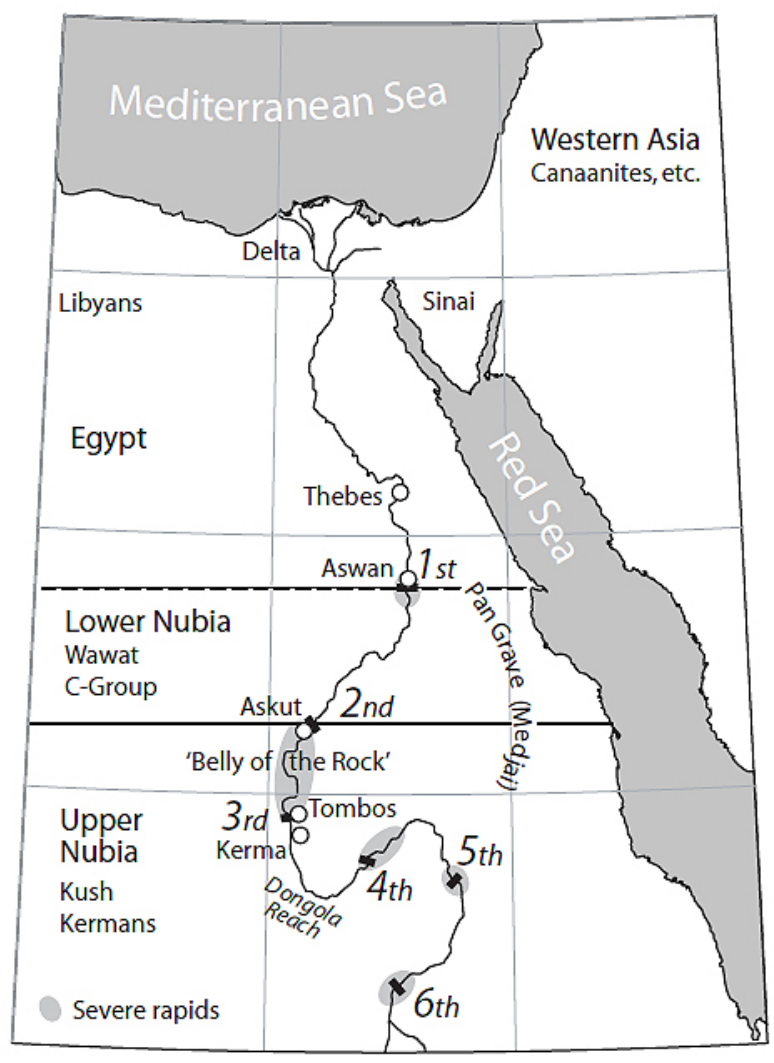

Figura 1: Mapa de Egipto y Nubia en el Reino Medio. Extraído de SMITH, 2003: 3.

Por otra parte, la cultura Kerma ha sido uno de los pueblos de los que más información se ha obtenido, gracias a las excavaciones de un equipo suizo en los últimos treinta años (BONNET et al., 2004; BONNET et al., 2000). En la ciudad de Kerma se han encontrado restos prehistóricos que demuestran una muy temprana sedentarización (HoNNEGGER, 2007: 208-211). Esta cultura experimentó un proceso de estratificación social que culminó en el Kerma Clásico —-Segundo Periodo Intermedio Egipcio-, aunque las estructuras fundamentales de gobierno ya habrían estado asentadas en el Kerma Medio (O’Connor, 1993: 29; Flammini, 2008: 52).

El último grupo, los medyaiu, era una sociedad nómada, equiparada con la cultura Pan Grave, denominada así debido a la forma de sus tumbas. Los egipcios diferenciaban a los nhsyw, nubios del valle del Nilo, y a los 
md $3 y$ w, que habitaban el espacio entre el Nilo y el Mar Rojo (Posener, 1958: 38-39). Constituían al mismo tiempo una amenaza para Egipto, soldados mercenarios de las fuerzas armadas y grupos de inmigrantes que trataban de asentarse en Egipto (DiEgo Espinel, 2006: 334).

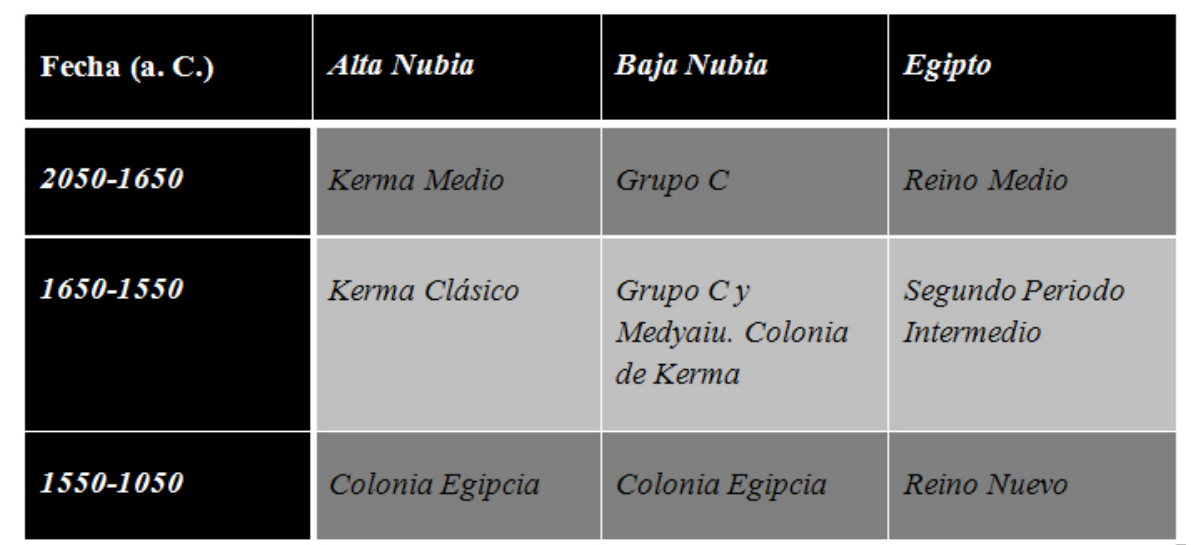

Tabla 1: Cronología comparada de Egipto y Nubia.

\section{LA VISIÓN ESTEREOTIPADA de LOS NUbios EN EL REINO MEDio}

La actitud oficial del estado egipcio hacia los nubios contrasta fuertemente con la evidencia arqueológica. Para los egipcios, los nubios formaban parte de lo que se denominaba los "Nueve Arcos", un grupo de regiones y pueblos que rodeaban a Egipto, y que estaban sometidos al poder del faraón, a nivel teórico al menos. Desde muy temprano, los egipcios fueron construyendo una identidad étnica que les diferenciaba de los "otros", siempre desde una perspectiva de superioridad. La ideología oficial siempre representaba a los egipcios como los seres superiores civilizados, frente a los pueblos bárbaros, cuyo peligro radicaba no en su capacidad o su ferocidad, sino en su gran superioridad numérica y su capacidad para agruparse (Liverani, 2003: 121). Pese a este peligro, las tierras extranjeras se consideraban llenas de recursos naturales que podían e incluso debían ser explotadas por los egipcios. En el caso de Nubia, el material quizá más obvio era el oro, pero también muchos materiales como inciensos, aromata y maderas que se importaban de Nubia para satisfacer las demandas de una clase social alta cada vez más próspera en el Reino Medio. Así pues el poder dominante en la zona, en este caso Egipto, creó un estereotipo étnico del pueblo "sometido" basado en la distinción, destinado a reforzar las estructuras de poder y de control ya existentes. Se trata por tanto, de una visión irreal de estas poblaciones nubias (SMITH, 2003: 20).

Esta visión queda reflejada en la literatura. El topos del extranjero le presenta como bárbaro y cobarde, inferior e incivilizado (LOPRIENO, 1988), y además se observa a través de numerosos textos y representaciones 
iconográficas. En la estela fronteriza del año 16 de Senusert III, que debe inscribirse más en el ámbito literario que histórico (EYrE, 1990), en la fortaleza de Semna se hace una descripción de los nubios:

[...] Ya que el silencio después de un ataque es fortalecer el corazón de los enemigos; ser agresivo es ser efectivo, y retirarse es una cobardía; es un verdadero afeminado quien es expulsado de su frontera. Ya que el nubio con solo [escu] char cae por la palabra, entonces responderle produce su acobardamiento/ retirada. Si uno es agresivo con él, provocal causa que se retire; si uno se retira, él se vuelve agresivo. No son gente (digna) de respeto, son despreciables y de corazón y brazos rotos [...] (Berlín 1157, líneas 9-13)

En este texto puede observarse perfectamente este topos de los nubios: cobardes, traicioneros y despreciables. Se trata de un pueblo sometido al poder del rey, que puede derrotarles tan sólo con una palabra. Esta visión desembocaría posteriormente, especialmente en el Reino Nuevo, en las escenas del rey aplastando a sus enemigos.

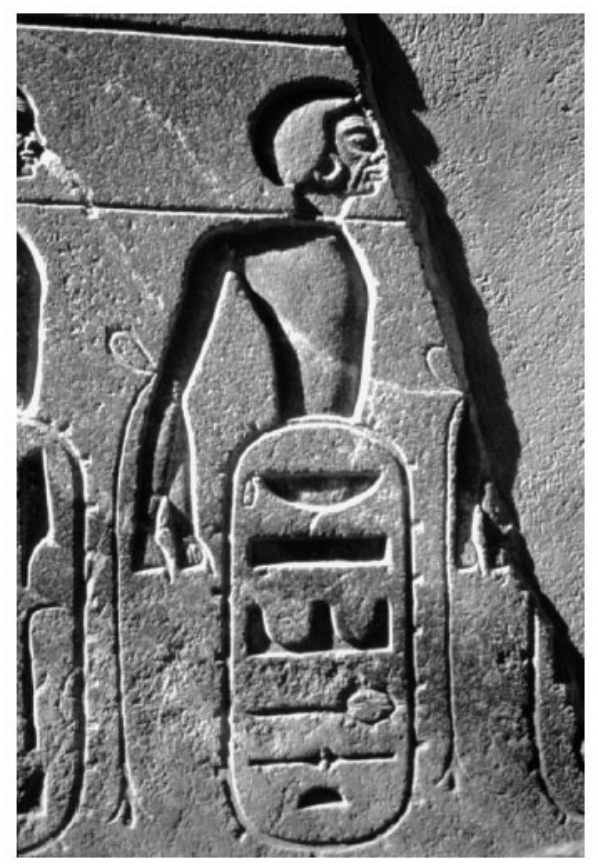

Figura 2: Representación de Kush vencido procedente de una estatua de Ramsés II del templo de Luxor. El texto es $k 3 \breve{s}$ hst "el cobarde Kush". Extraído de Sмiтн, 2003: 12. 
Esta caracterización del extranjero como portador del caos, responde a la dualidad de la lucha entre el "yo" y el "otro", como una representación mundana de la lucha entre mAat e isft, el orden y el caos. Pese a que esto fue así para todos los extranjeros, en el caso de los nubios parece que la hostilidad fue mayor, probablemente porque también lo era la amenaza que suponía para las fronteras egipcias.

Otro de los ejemplos más importantes a este respecto son los Textos de Execración, textos inscritos generalmente sobre figuras de barro cocido representando a los enemigos de Egipto. Se trata de unas figuras empleadas en rituales de execración con el objetivo de debilitar ritualmente a los enemigos, bien sea mediante la simple inscripción de sus nombres bien con fórmulas más complejas. La práctica de estos rituales se extiende desde el Reino Antiguo hasta la época romana, y en el Reino Medio su práctica estaba estandarizada (MuHLESTEIN, 2008: 2). La estandarización de los textos, el deseo de proteger el estado y a sus gobernantes, y el conocimiento de las políticas y estructuras extranjeras demuestran que eran ritos promovidos por el estado (ibid.). Los objetos con los que se practicaban estos rituales se rompían, se enterraban o se quemaban. Hay una cantidad importante de depósitos que contenían objetos relacionados con estos rituales (Sethe, 1926; Posener, 1940; Koenig 1990), algunos de los cuales adoptan la forma de figuras de prisioneros enemigos inscritos generalmente con listas de nombres de pueblos, dirigentes, o etnias, aunque tampoco es extraño encontrarlos sin inscripciones. Además, la parte dedicada a los nubios en estos textos generalmente aparece en primer lugar en los listados de enemigos, indicando el grado de importancia de los vecinos del sur dentro del espectro de posibles enemigos de Egipto.

Otra forma de aparición del topos del nubio en el Reino Medio es el desarrollo del calificativo "cobarde, miserable" (Xst) (LORTON, 1973). Este adjetivo se aplicaba generalmente en inscripciones egipcias siempre que el texto se refería a Nubia (kAS XSt), en una acción que perseguía ensalzar las virtudes de la etnicidad egipcia mediante los defectos de "los otros" (Sмiтh, 2003: 1).

Frente a esta visión estereotipada de la ideología oficial faraónica, en las fuentes se puede intuir una realidad diferente. En primer lugar, los egipcios, pese a considerar en este tipo de inscripciones a los nubios como cobardes, los empleaban en el ejército desde comienzos del Reino Medio, y fueron uno de los pilares fundamentales en los ejércitos de los grandes nomarcas durante la reunificación del país (FISCHER, 1961). Además, en los textos en los que no se pretendía ofrecer una imagen estereotipada de la identidad étnica de los nubios, sino su mimesis, se muestra cómo las relaciones entre egipcios y nubios se producían a niveles mucho más personales. En la Historia de Sinubé, por ejemplo, el héroe egipcio es acogido por el líder asiático, y favorecido como un hijo. Además, cuando se ve 
obligado a enfrentarse al campeón de los asiáticos, él mismo percibe que es considerado por éstos como inferior debido a su origen egipcio.

(...) Soy como un toro apartado en una manada extraña, al que el toro de la manada ataca, (...) ¿Es un inferior querido cuando se convierte en superior? Ningún asiático se hace amigo del hombre del delta. ¿Qué haría que el papiro se parta ante la montaña? (...)(LiCHTHEIM, 1973: 227)

Esta percepción de la conciencia de identidad étnica de los extranjeros refleja que, pese a la imagen de animales que se transmite en los textos tópicos, el conocimiento sobre ellos que tenían los egipcios era mayor.

Algo similar se aprecia en el himno de la misma Historia de Sinubé, en el que al final se dice:

(...) Uno que agranda las fronteras, conquistará las tierras del sur, ignorando las tierras del norte, a pesar de haber sido creado para golpear al asiático y pisar a los beduinos (...) (LichTHEIM, 1973: 226)

Esta conciencia de la identidad étnica de otros grupos se plasma en el hecho de que en este elogio al faraón, pronunciado supuestamente ante el mandatario asiático, se habla de la beligerancia — siempre legítima para los egipcios- hacia Nubia, pero se matiza con respecto a los asiáticos, quienes estaban escuchando el discurso. Pese a que se admite que el faraón tenía la misma capacidad para aplastar a cualquiera de sus enemigos, el discurso se modificaba en los matices en función de la audiencia.

Este conocimiento se observa más claramente se tienen en cuenta otros textos fuera del ámbito de la literatura. La estela anteriormente citada de Senusert III se situaba en el límite de la literatura y el documento oficial. Otros textos de la misma región y la misma época arrojan algo de luz sobre la percepción de los nubios por parte de los egipcios. La primera estela de Semna, por ejemplo, regula los mecanismos de control de la frontera meridional egipcia en los siguientes términos:

Frontera meridional establecida en el año 8 bajo la majestad del Rey Dual [JakauTre iQue le sea dada vida por siempre y hasta la eternidad!, para que no se permita que ningún nubio la pase navegando río abajo ni viajando por tierra ni (viajando) en barco, ni ningún ganado de los nubios, excepto el nubio que venga a hacer intercambio en Iqen o en asunto oficial. Que sean realizadas todas las cosas buenas con ellos sin permitir que pase ningún barco de los nubios río abajo por Heh hasta la eternidad. (Berlín 14753) 
En este caso, a diferencia de los textos vistos hasta ahora, en los que el nubio era caracterizado como el enemigo y "cobarde", aquí se les considera personas a las que hay que controlar. El hecho de que se contemple la posibilidad del intercambio, y más aún el hecho de que haya nubios que acudan a Egipto "en asunto oficial" demuestra que las relaciones reales entre egipcios y nubios eran más cercanas de lo que deja entrever la ideología oficial, incluso a los más altos niveles.

\section{LA OTRA VISIÓN DE LOS NUBIOS: ARQUEOLOGÍA Y TEXTOS NO OFICIALES}

Hasta ahora se han analizado distintos tipos de textos y fuentes, todos ellos egipcios, en los que se transmite una determinada visión de los extranjeros, y más concretamente de los nubios. Se ha visto cómo el desprecio hacia el "otro" ayuda a la construcción de una identidad étnica, pero ¿se corresponde esta visión con los datos que aporta la arqueología?

La Baja Nubia es una región muy apta para este tipo de estudio por dos razones principalmente: en primer lugar, se trata de una zona donde coexistieron durante todo el Reino Medio egipcios y nubios, junto con los medyaiu y los habitantes de los asentamientos de la cultura Kerma más al sur. Los restos arqueológicos derivados de esta convivencia permiten analizar cuestiones más cotidianas que las que muestran los textos. Esto lleva directamente a la segunda razón, que es la gran cantidad de trabajos arqueológicos realizados en Nubia a raíz de la campaña de salvamento de la UNESCO con motivo de la construcción de la gran presa de Asuán. Aunque dichos trabajos a su vez conllevan implícito un grave problema, y es que muchas de las zonas estudiadas se encuentran actualmente sumergidas.

En cualquier caso, con los datos que se poseen, la gran característica a nivel arqueológico de la Baja Nubia es la red de fortificaciones que los egipcios levantaron para proteger su frontera meridional. Esta red se extendía desde Elefantina hasta Semna Sur, en Batn el-Hagar, y a finales del Reino Medio estaba compuesta por al menos 13 fortalezas, aunque cada una pudo tener una función diferente a parte de la defensiva. De hecho, en prácticamente todas las fortalezas se han encontrado instalaciones dedicadas al trabajo o al comercio, aunque lamentablemente el grado de conocimiento de los distintos recintos es muy desigual.

Por tanto, parece que se puede afirmar que las fortalezas, además de una función claramente defensiva, cumplían otros objetivos. En primer lugar, servían como punto de partida de las patrullas fronterizas (pXrt), que se encargaban de la localización de grupos humanos que hubieran traspasado la frontera desde el sur, y posiblemente de la persecución y captura de los desertores del estado egipcio ${ }^{2}$. Es de destacar en este punto que estas patrullas

2 Estos desertores de los trabajos que todos los egipcios debían realizar para el estado supusieron un auténtico problema. En el Reino Nuevo, hubo una gran actividad diplomática 
fronterizas estaban en ocasiones conformadas por medyaiu, posiblemente debido al conocimiento del terreno y a su adaptación a un medio tan hostil como el desierto.

Por otro lado, en las fortalezas se fue desarrollando un modelo de asentamiento que evolucionó desde una población compuesta por soldados que cumplían su servicio y volvían a Egipto, hacia un asentamiento sedentario. A medida que avanzaba el Reino Medio y en una tendencia que continuó hasta el II Periodo Intermedio las fortalezas fueron ganando en autonomía, y las necrópolis fueron creciendo. Los datos de dataciones de las estelas funerarias de Buhen confirman esta tendencia, ya que las estelas aumentan en número a medida que avanza el tiempo, demostrando que cada vez más egipcios se enterraban allí en lugar de volver a Egipto (SмiтH, 1995: 51), así como los datos obtenidos del estudio de los materiales cerámicos de la fortaleza de Askut (Sмiтh, 2003: 191).

Asimismo, las cerámicas halladas en las necrópolis de la cultura Kerma muestran una gran regularidad en la aparición de cerámica egipcia a lo largo de todo este periodo, con una tendencia, en la que hasta la dinastía XII la cerámica predominante es del Alto Egipto. A partir de ese momento predomina la cerámica procedente del Bajo Egipto, y a finales de la dinastía XIII, vuelve a aparecer sólo la del Alto Egipto (BOURRIAU, 2004). La explicación de esta tendencia es sencilla: con el traslado en la dinastía XII de la capital de Tebas a Ity-tauy, la cerámica enviada a las fortalezas proviene de allí. Al final de la dinastía XIII, con el derrumbe de la monarquía, los contactos se vuelven a limitar al Alto Egipto ${ }^{3}$.

Esta tendencia al sedentarismo y a la autonomía tanto política como económica de las fortalezas se ve confirmadas por el empleo de la cerámica funcional nubia como egipcia en el ámbito interno de las fortalezas. Las excavaciones de Askut han revelado que el asentamiento comenzó siguiendo una planta y un diseño ortogonal, perfectamente planificado, que a medida que avanzaba el tiempo se fue descuidando según se ampliaban edificios y sectores sin una planificación previa para albergar a las familias de los soldados (SмiтH, 1995: 51-66). Algo similar sucede con los datos del análisis de las tipologías cerámicas, ya que la cerámica de servicio fluctúa entre tipos egipcios o nubios en función del control de Egipto sobre la fortaleza, empleándose como un medio más para crear una identidad étnica, ya que cuando el control de las fortalezas pasa al reino de Kush, la cerámica de servicio era eminentemente nubia (SMITH, 2003: 190-192). Sin embargo, la cerámica de cocina se mantuvo constantemente con tipos principalmente

relacionada con estos prófugos, que además de debilitar al Estado egipcio por el trabajo que perdía y los recursos que empleaba en frenar estas deserciones, fortalecía a sus enemigos. (LiverANi, 2003: 95-103).

3 Al final del Reino Medio Egipto perdió el control de las fortalezas, que pasaron a estar en el ámbito de influencia de Kerma. 
nubios, debido posiblemente a que el personal empleado para el servicio en las fortalezas eran nubios, que en un ámbito privado como la cocina, seguían utilizando aquellos artefactos con los que estaban familiarizados (Sмith, 2003: 192).

Smith ha planteado también a partir de los datos de las excavaciones de Askut que la abundancia de objetos de culto relacionados con la fertilidad, donde las influencias nubias parecen más importantes, lleva a considerar la posibilidad de matrimonios entre egipcios y nubias que viviesen en la fortaleza (SMITH, 2003: 133).

Como se puede observar, estos análisis arqueológicos apuntan a una interacción entre egipcios y nubios mucho más compleja de lo que en un principio sugieren las fuentes egipcias.

Pero, además de la arqueología, hay algunos textos cuya naturaleza permite asomarse a esta vida cotidiana en la frontera meridional egipcia. Se trata de los Despachos de Semna, una serie de papiros hallados en el Ramesseum de Tebas que contienen fragmentos de informes enviados a un alto funcionario en Tebas desde las fortalezas. Los documentos están datados en el año 3 de Amenemhat III ${ }^{4}$.

En estos documentos se observa cómo se llevaba a cabo el control de los movimientos de los nubios por parte de los egipcios, así como el comercio en las fortalezas. El primer despacho

\section{(...) la fortaleza}

de Semna, (donde) llegaron [...] nubios en el año 3, mes 4 de peret, día 4[+3] a la hora de la [tarde] para comerciar. Se comerció lo que habian traído [...] comercio de allí. Entonces ellos navegaron río arriba hacia el lugar de donde babian venido, y se les dieron pan y cerveza como [...] (...) (despacho no 1, líneas 7-9, Smither, 1945: 3-10)

\section{(...) Otros seis nubios llegaron a la fortaleza de Semna para} comerciar [...] en el mes 4 de peret, día 8 . Se comerció lo que babian traído. Ellos navegaron río arriba bacia el lugar del que venían en este día. (despacho $\mathrm{n}^{\circ} 1$, líneas 12-13, SMITHER, 1945: 3-10)

Como puede apreciarse, el texto relata la llegada a una fortaleza de grupos de nubios en dos días consecutivos. A estos nubios se les permitía comerciar y se les proporcionaba pan y cerveza, en un gesto de hospitalidad.

4 Esta datación se hace por la aparición en uno de los documentos de Samontu, que aparece en otros documentos del reinado de Amenemhat III (FrANKE, 1984: 319 (526)). 
El comercio era muy importante tanto para egipcios como para nubios, pero las fortalezas eran también una oportunidad de conseguir trabajo, como demuestra otro de los despachos:

(...) Es una comunicación para ti, que estés sano y vivo, acerca de que 2 medyai y 3 mujeres medyai y 2 [...] vinieron del desierto en el año 3, mes 3 de peret, día 27. Ellos dijeron: "venimos a servir al Palacio iv. p. s.l" Se les preguntó sobre la condición del desierto. Entonces ellos dijeron: "No bemos escuchado ninguna cosa, esta tierra está muriendo del hambre", asi dijeron. Entonces este sirviente biro que se les enviara a su desierto en este día. Entonces una de estos medyai dijo: "Que me sea dado mi medyai en [...]" Entonces dijo este medyai: " $\mathrm{i}$ Acaso se retira uno que comercia?" (despacho no 5, líneas 7-12, SMither, 1945)

En este documento, se aprecia que los nubios, obligados por una mala situación - posiblemente una hambruna - acuden a la fortaleza "a servir al palacio". Los egipcios no les permiten entrar, aunque parece que sí permitieron a alguno de ellos entrar a comerciar. Conviene recordar en este punto que la estela de Semna de Senusert III establecía como punto de comercio en la región la fortaleza de Mirgissa, pero queda claro que esto se llevaba a cabo a un nivel local.

\section{Conclusiones}

Se ha podido observar en distintos documentos las diferentes perspectivas de los egipcios a la hora de tratar el tema nubio. Desde los textos más literarios y oficiales, en los que los nubios son tratados dentro de un estereotipo de enemigo cobarde y huidizo, hasta documentos cotidianos en los que los nubios aparecen como los habitantes de la región fronteriza del sur de Egipto. Esta información, completada con los datos obtenidos de las diferentes excavaciones arqueológicas de la zona, ofrece un panorama mucho más complejo del que inicialmente planteaban las fuentes egipcias. Por lo tanto, parece claro que los nubios no eran sólo un enemigo tradicional, eran aliados en las fuerzas armadas, eran comerciantes, preparaban los alimentos de los egipcios residentes en las fortalezas y les ayudaban en las patrullas gracias a su conocimiento del terreno.

En primer lugar, los tópicos étnicos de los textos literarios egipcios, así como los textos de execración, habrían tenido como objetivo aumentar la moral de los soldados de las guarniciones egipcias frente a un enemigo cuya fama en esa región distaba mucho de ser de cobardes. Asimismo, las 
excavaciones de Kerma revelan a un interlocutor con un poder en ascenso muy a tener en cuenta, y que provocó que Egipto realizase uno de los mayores esfuerzos constructivos de todo el Reino Medio con la construcción de la red de fortalezas de la Segunda Catarata, que a la postre acabarían prestando su lealtad al rey de Kush en el segundo Periodo Intermedio.

En segundo lugar, las abundantes y exhaustivas patrullas fronterizas destinadas a controlar las migraciones tanto de nubios a Egipto como de fugitivos egipcios a Nubia demuestra que la frontera meridional, lejos de ser una línea definida, era un limes permeable. Se produjo un proceso similar de migraciones como el que se dio en el norte con grupos de asiáticos que acabarían haciéndose con el poder. En el caso de Nubia, parece que estos flujos migratorios se controlaron con bastante eficacia, mientras el estado tuvo la suficiente fuerza para controlar estas fortificaciones.

En tercer lugar, tanto los textos como los datos arqueológicos demuestran que para Egipto la zona de la Baja Nubia era de vital importancia, tanto por sus valiosos recursos materiales como por el valor estratégico como primera zona de defensa ante Kerma, un reino al que los egipcios debieron tener muy en cuenta como posible amenaza.

Por tanto, con las evidencias que se han analizado, puede observarse que el conjunto de datos apunta a que estas relaciones fueron de hecho mucho más complejas que lo que los textos por sí solos quieren mostrar. Los grupos étnicos fuertemente constituidos como el egipcio ofrecen una sola visión del grupo frente a los extraños, en este caso los nubios, pero esta fachada es porosa, y el examen detallado permite ver los resquicios en los que las dinámicas de intercambio cultural se desarrollan. Lejos de ser animales cobardes que sólo pueden convertirse en amenaza gracias a la desidia egipcia, como proclama la estela de Senusert III, para los egipcios que protegían la frontera, los nubios eran casi con total seguridad compañeros de armas, amigos, esposas, comerciantes, y, en el peor de los casos, un enemigo temible y respetable que llevó a los faraones de la dinastía XII a la construcción de una de las redes defensivas más importantes de la Antigüedad.

\section{BIBLIOGRAFÍA}

Bonnet, Ch. y Valbelle, D., (2004), Le temple principal de la ville de Kerma et son quartier religieux, París

Bonnet, Ch.; Valbelle, D. y Privati, B., (2000), Edifices et rites funéraires à Kerma, París.

Bourriau, J., (2004), «Egyptian Pottery found in Kerma Ancien, Kerma Moyen and Kerma Classique Graves at Kerma»,en Kendall, T. (ed.), Nubian Studies 1998: Proceedings of the Ninth Conference of the International Society of Nubian Studies, August 21-26, 1998, Boston, Massachusetts, Boston, pp. 3-13. 
Diego Espinel, A., (2006), Etnicidad y territorio en el Egipto del Reino Antiguo, Barcelona.

Eyre, C. J., (1990), «The Semna Stelae: Quotation, Genre, and Functions of Literature», en Israelit-Groll, S. (ed.), Studies in Egyptology presented to Miriam Lichteim, 2 vols., Jerusalén, pp. 134-165.

Fischer, H. G., (1961), «The Nubian Mercenaries of Gebelein during the First Intermediate Period», Kush 9, pp. 44-80.

Flammini, R., (2008), «Ancient Core-Periphery Interactions: Lower Nubia During Middle Kingdom Egypt (ca. 2050-1640 b.C.)», Journal of World-Systems Research XIV, n 1 , pp. 50-74.

Franke, D., (1984), Personendaten aus dem Mittleren Reich, Wiesbaden. 212.

Honegger, M., (2007), «Aux origines de Kerma», Genava LV, pp. 201-

Koenig, Y., (1990), «Les textes d'envoutement de Mirgissa», RdE 41, pp. 101-125.

Lichtheim, M., (1973), Ancient Egyptian Literature: a book of readings, vol. I. The Old and Middle Kingdoms, Berkeley.

Liverani, M., (2003), Relaciones internacionales en el Próximo Oriente antiguo, 1600-1100 a.C., Barcelona.

Loprieno, A., (1988), Topos und Mimesis. Zum Ausländer in der ägyptischen Literatur, (Äg. Abh. 48), Wiesbaden.

Lorton, D., (1973), «The So-called "Vile" Enemies of the King of Egypt (in the Middle Kingdom and Dyn. XVIII)», JARCE 10, pp. 65-70.

Muhlestein, K., (2008), «Execration Ritual», en Dieleman, J. y Wendrich, W. (eds.), UCLA Encyclopedia of Egyptology, Los Angeles, http:// digital2.library.ucla.edu/viewItem.do?ark $=21198 / \mathrm{zz000s} 3 \mathrm{mqr}$ (Consulta 22-02-2011).

O’Connor, D., (1993), Ancient Nubia: Egypt's Rival in Africa, Pennsylvania,.

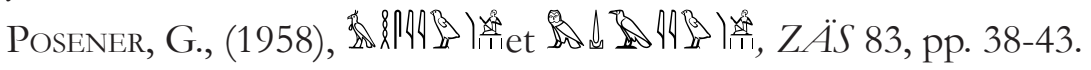

Posener, G., (1940), Princes et Pays d'Asie et de Nubie. Textes hieratiques sur des figurines d'envoûtement du Moyen Empire, Bruselas.

SETHE, K., (1926), Die Ächtung feindlicher Fürsten, Völker und Dinge auf altägyptischen Tongefässcherben des mittleren Reiches, nach den Originalen im Berliner Museum, Berlín.

Sмiтн, S. T., (1995), Askut in Nubia, Londres.

Smith, S. T., (2003), Wretched Kush. Ethnic identities and boundaries in Egypt's Nubia Empire, Londres y Nueva York. 
Smither, P. C., (1945), «The Semnah Despatches», JEA 31, pp. 3-10. Trigger, B., (1965), History and Settlement in Lower Nubia, Yale. 